


\section{Some Pedagogical Reflections}

\section{Freya Kodar}

It is always more challenging, and a little nervewracking, to deliver an instructional unit someone else has pulled together, even when there has been significant discussion amongst, and input from, the instructional team. This was particularly so for the Insite unit because we were using some "unconventional" texts and teaching methodologies. The material under discussion was both intellectually and personally challenging for many, and it was our first time delivering it. I offer some reflections as a member of the teaching team on the ways in which these particular challenges together produced a rich and exciting unit to teach, and if the student feedback is any indication, provided a significant learning experience.

\section{The "unconventional" texts and teaching methodologies}

The unit began in the fall with an assignment on the trial judgment in PHS Community Services Society v Canada (Attorney General). ${ }^{1}$ In the Spring session, we used several methodologies to encourage discussion and analysis of the case and to deepen students' understanding of law in its social context. These were:

1. Viewing and discussing the film, Fix: The Story of An Addicted City; ${ }^{2}$

2. Watching and analyzing a panel discussion with a variety of speakers who had a role in the creation or continuance of the Insite facility; ${ }^{3}$

3. Re-reading and analyzing the trial decision, including the interjurisdictional immunity analysis that had not been included when the students studied the case in the previous September;

4. Viewing and analyzing Staying Alive, ${ }^{4} \mathrm{a}$ Fifth Estate feature that focuses on Insite's operations and the people who access its services;

5. A mapping exercise.

\section{Fix: The Story of an Addicted City and Staying Alive}

The filmic texts provided a considerable amount of the unit's content and context. Filmed over a two-year period, Fix: The Story of an Addicted City chronicles the social reality of drug addiction and overdose deaths in Vancouver's Downtown Eastside (DTES) and the political efforts to create a safe injection site. Those involved in the political process, including activists Dean Wilson and Ann Livingston from the Vancouver Area Network of Drug Users (VANDU); Philip Owen, the city's mayor at the time; and other participants in the political process who hold varying opinions about the merits of a harm reduction approach and a safe injection site, present their perspectives and experiences directly to the viewer. Staying Alive focuses on Insite itself-its operations and staff, and the people who use its services. In viewing Fix, students were asked to consider four questions:

1. Who speaks, and what do they tell us? (about self, others, drugs, the DTES, law); 
2. What sources of authority are used? (science, religion, economics, experience, law);

3. What does the film foreground as significant? (what is relevant? what is unspoken?); and

4. What is ultimately the film's argument (who/what is judged, what are they guilty of)? ${ }^{5}$

Although mediated by the directors' editorial choices, both filmic texts allowed students to hear people in their own voices, and to view the political process as it unfolded. The films also showed some harsh realities of drug use and poverty in the DTES, realities that were narrowed and sanitized by the time they formed part of the court decision "text." Tim Richards writes of the ways in which the Insite unit provided important social context for students, particularly in terms of understanding "the perspectives and experiences of those whose lives would be affected by the closure of Insite." The filmic texts played a critical role as they provided a visual and aural window into these lives that spoke to students on the affective domain without spilling over into voyeurism, and provided important context for understanding the court decision. Such a view could not have been replicated with transcripts, affidavits, judgments and other written texts.

In previous years, we have had students work with complex social and political problems through a multi-party negotiation roleplaying exercise. In my experience, it was difficult to prepare students adequately to role play parties and perspectives, and it often seemed that the success or failure of the negotiation overshadowed efforts to understand the social and political context of the problem. Moreover, at times it was difficult for students to participate in a hypothetical problem that was very familiar to them personally, or to experience the perceptions of classmates about the issue or particular roles. The filmic texts and the format of the Insite unit did not entirely eliminate these difficulties, but they did alleviate them to some extent since the people in Fix and Staying Alive, along with members of the panel discussion, were "playing themselves." Clearly, students were differently situated in terms of their personal experience, understandings and opinions about drug use, poverty, harm reduction and a safe injection site, but they were able to use the filmic texts and the panel to both expand their understandings, and as vehicles through which to articulate their own positions.

In addition to providing context, the filmic texts also provided a locus for students to think about perspective, evidence and argument. Film is an unexpected text for most law students and one that we had rarely used in the Legal Process course. Thus it was important to provide students (and faculty) with some guidance on "reading" filmic texts. Rebecca Johnson's introductory session before the viewing of Fix encouraged students to analyze (1) the perspectives of those portrayed in the films, (2) the arguments and the evidence they relied on in support of their positions, and (3) places of agreement and disagreement-a useful analytical approach for reading cases and resolving real legal problems.

\section{Mapping}

Working with the filmic texts and the panel discussion in this way set the stage for the mapping exercise that brought everything together-the social and political context and the role of law (in the broadest sense) in creating and resolving the problem. Students had to work together and draw on the perspectives and arguments in the materials and discussions to create their group's map. One important benefit of this approach was that they did not necessarily have to position themselves in relation to the merits of safe injection sites or the litigation to produce a comprehensive map.

I have to admit that, at the time, mapping was out of my teaching comfort zone, so I approached facilitating the mapping session with some trepidation. Despite their initial uncertainty about how to proceed, the students produced interesting and thoughtful maps.? There was much to explore in discussion of each map and the connections amongst them. I am now a mapping "convert," and have used the meth- 
odology in other classes to facilitate student discussion and analysis of complex material or problems.

\section{"Timing"}

Finally, a few words on timing and luck. Students initially encountered the problem in an edited trial judgment they had to brief and comment on to complete the fall legal process component of the curriculum. At this point, they had two weeks of introduction, and their own assumptions to ground their understanding of the case. In January, they were given the full trial judgment, which now included the interjurisdictional immunity analysis that had been edited for the fall assignment, and they were asked to review their original assignment. This return to the case and the assignment gave them the opportunity to see how much they had learned since September (despite what their December examination results might have suggested).

We had hoped that the Court of Appeal decision would be released before the spring component started. However, the fact that it came down the day after it ended-after students had listened to people who were named plaintiffs in the case, and to lawyers who had argued it, and to people they had seen in the film-was exciting. It did make it "real" in a very particular way. Students' engagement with the case, the issues and the controversies through the Insite unit, and their fall term course work, meant they were able to read and understand the judgment. The timing also created an enthusiastic and well-informed audience for the subsequent faculty panel on the Court of Appeal decision. $\mathrm{Had}$ it been later in the term student engagement might have waned as examinations and other assignments loomed. Moreover, the timing of the decision's release meant that faculty were thinking about the case through a "first year legal process" lens as well through our disciplinary areas of interest which also contributed to a robust panel discussion.

While it is hard to imagine teaching the unit in this fashion again, given all the pieces that had to fall into place, the unit's structure and methodologies serve as a template for fu- ture cases, and for thinking about ways to teach complex social and political problems in our discrete subject area classes. And who knows ... maybe the Supreme Court of Canada will release its appeal decision next January.

\section{Notes}

* Assistant Professor, Faculty of Law, University of Victoria.

12008 BCSC 661.

2 Dir. Nettie Wild, 2005, Canada Wild Productions, Vancouver.

3 The panel included Ann Livingston and Jackie Robinson of the Vancouver Area Network of Drug Users (VANDU); Philip Owen, former mayor of Vancouver; Heather Hay, Director of Addiction, HIV/AIDS and Aboriginal Health Services, Coastal Health Authority; Sheila Tucker, Counsel for the Coastal Health Authority in the Appeal; Paul Riley, Counsel for the Attorney General of Canada; and Doug Lang, Police Officer, Downtown Eastside. See Richards infra for more details about the panel.

4 Dir. Tamar Weinstein, 2009. First aired on March 13, 2009 as an episode of CBC-TV's the fifth estate.

5 Rebecca Johnson, "Nettie Wild's "Fix: The Story of an Addicted City" (2002) Notes for Viewing 'Law' in Film." The full viewing instructions distributed to students are available online at http://insite. law.uvic.ca.

6 Infra at http://insite.law.uvic.ca.

7 See Rebecca Johnson's discussion of the maps produced in her class, which are also reproduced infra. 